\title{
Enzymatic hydrolysis of steam-exploded sugarcane bagasse by adding natural Sapindus peel
}

\author{
${ }^{1}$ Y.Z. YOU \& ${ }^{2}$ Y.M. WANG \& ${ }^{3}$ B.C. Q.S \& ${ }^{4}$ J.X. JIANG* \\ ${ }^{1}$ Department of Chemistry and Chemical Engineering, ${ }^{2} \mathrm{MOE}$ Engineering Research Center of Fo- \\ restry Biomass Materials and Bioenergy, ${ }^{3}$ Beijing Forestry University, ${ }^{4}$ Beijing 100083 , China
}

KEYWORD: sugarcane bagasse; steam-explosion; enzymatic hydrolysis; Sapindus peel

ABSTRACT: Steam explosion pretreatment was a feasible method to treat sugarcane bagasse. The results showed that the hemicelluloses can be effectively removed during the pretreatment and increase the ability of enzymatic hydrolysis. The highest glucose yield was achieved at $74.99 \%$, which was increased by $57.86 \%$ with the same enzyme loadings $30 \mathrm{FPU} / \mathrm{g}$-cellulose compared with the untreated sugarcane bagasse. The glucose yield of steam-exploded sugarcane bagasse can be significantly improved from $36.46 \%$ to $74.99 \%$ with the increment of cellulase. Sapindus peel contained natural surfactant can evidently reduce the surface tension of hydrolysis broth and improve the ability of enzymatic hydrolysis at an economic concentration $(1.2 \mathrm{~g} / \mathrm{L})$. The highest glucose yield was of $80.99 \%$ with cellulase loading of 10 FPU/g-cellulose and addition of $1.2 \mathrm{~g} / \mathrm{L}$ Sapindus peel, which suggest that $10 \mathrm{FPU} / \mathrm{g}$-cellulose was suitable for lignocellulose saccharification industry.

\section{INTRODUCTION}

Sugarcane, Saccharum officinarum L., a potentially ethanol and sugar source, was first grown in Southeast Asia and Western India (Hofsetz et al. 2012). In 2012, Brazil has been producing around 580 million tons of sugar cane and 174 million ton of bagasse, a solid waste resulting from juice extraction (Boscolo et al. 2014). The utilization of biomass for transport fuels, chemicals, and materials is increasing because of the shortage of fossil fuels and the need to reduce greenhouse gas emissions ( $\mathrm{Yu}$ et al. 2013). Therefore, it would be worthwhile to remain such cellulose-rich wastes for the production of bioethanol.

Lignocellulose is considered as a potential resource for the production of second generation ethanol, which can provide transportation fuel without threatening the food supply and biodiversity (Cao et al. 2012). The typical process of converting lignocellulose to fermentable sugars (especially glucose) is enzymatic hydrolysis. However, different pretreatments lead to materials with different characteristics, which influence the enzymatic hydrolysis. The appropriate choice of a pretreatment can be determinant for the process economical and technical viability, and should be made considering aspects of the whole process (Tao et al. 2011), including the energy input and output and the environmental impact (Andrade et al. 2014).

The presence of lignin in biomass substrates could inhibit enzymatic hydrolysis. Specifically, lignin modified by a dilute acid at high temperature led to better enzyme-lignin binding ( $\mathrm{Yu}$ et al. 2013).

The surfactant could reduce the surface tension of hydrolysis broth and decrease ineffective adsorptions of the cellulase on cellulosic substrate. Moreover, it could improve efficiency of cellulase to the fiber and avoid inhibition of lignin to cellulolytic enzymes. Hence, the adding of surfactant may enhance enzymatic hydrolyzation of the lignocellulose (Feng et al. 2012). Sapindus peel is an excellent raw material for production of natural non-ionic surfactant. Sapindus saponin performs high level of surface activity and functions of foam, emulsion, and scatter, and it could also avoid the secondary pollution on the environment. Therefore, it could be utilized as the surfactant in the lignocellulosic enzymatic hydroly-zation (Kim et al. 2007; Zhao et al. 2013). 


\section{MATERIALS AND EXPERIMENT}

\section{Materials and Steam explosion pretreatment (SE)}

Sugarcane bagasse was kindly provided by Guitang Corporation (Guangxi, China). The dry sugarcane bagasse was divided into two parts. One was ground and screened with 40 meshes. Those through the 40 meshes were collected as the experimental samples. The chemical composition of the raw material is $52.48 \%$ cellulose, $23.70 \%$ hemicelluloses, $21.12 \%$ lignin and $2.38 \%$ ash. The other was steam pretreated at $1.906 \mathrm{Mpa}$ for $5 \mathrm{~min}$ after impregnated with $4 \%$ sulfuric acid for one hour, which led to a relatively higher cellulose content of $58.82 \%$ and also a higher lignin content of $29.15 \%$. The in-soluble residue was collected and stored at $4{ }^{\circ} \mathrm{C}$. All chemicals used in this study were analytical grade.

\section{Sapindus peel (SP) preparation}

The peel of Sapindus fruits was manually separated from the seeds $(13 \mathrm{~mm} \times 8 \mathrm{~mm} \times 6 \mathrm{~mm})$ and dried in air. The air-dried Sapindus peel was then milled to nominal sizes of 40-60-mesh.

\section{Enzymatic hydrolysis}

Enzymatic hydrolysis of untreated and pretreated sugarcane bagasse was performed at $48{ }^{\circ} \mathrm{C}$ and $\mathrm{pH}$ 4.8 with a substrate concentration of $5 \%(\mathrm{w} / \mathrm{v})$ in a shaking incubator at $150 \mathrm{rpm}$ for $72 \mathrm{~h}$. The filter paper activity of cellulase (Celluclast 1.5 L, Sigma Co., St. Louis, MO, USA) was 74 filter paper unit (FPU)/mL, and the cellobiase activity of Novozyme188(Sigma Co.) was 175 cellobiase units $(\mathrm{CBU}) / \mathrm{mL}$. The cellulase loading for the substrate was 10-30 FPU/g-cellulose. $\beta$-glucosidase was supplemented to limit the end-product inhibition with an activity ratio of cellobiase units to filter paper units of 1:1.5. The loadings of Sapindus peel for the total volume were 0.6-1.5 g/L. Other hydrolysis experiments without surfactant were conducted for comparison. Samples were withdrawn and centrifuged at $10,000 \times g$ for $10 \mathrm{~min}$.

\section{Analytical methods}

The composition in raw and steam pretreated samples were analyzed according to the NREL analysis method for biomass. Samples were filtered through a $0.22 \mu \mathrm{m}$ filter and diluted appropriately by distilled water. Sugars were analyzed by HPLC (Waters 2695e, USA) with an Aminex HPX-87P column $(300 \times 7.8 \mathrm{~mm}$ : Bio-Rad, USA) and refractive index detection detector. Distilled water was used as the eluent, at a flow rate of $0.6 \mathrm{ml} / \mathrm{min}$. Each point is the average of duplicate experiments. The surface tension of the liquid before and after enzymatic hydrolysis was determined using the JK99B full automatic tension meter.

\section{RESULT AND DISCUSSION}

\section{Glucose Yields}

Glucose yield, expressed in percentage, was calculated on the basis of the ratio of glucose released from the cellulose to the glucose weight of the loading sugarcane bagasse. Glucose yields after $72 \mathrm{~h}$ in the digests of material and steam-exploded sugarcane bagasse with different enzyme loading (Fig. 1) and Sapindus peel loadings (Fig. 2) were investigated. It has been suggested that the increased porosity and the removal of hemicelluloses increase the accessibility of the pre-treated material (Ahvazi et al. 2007; Yang et al. 2004). As it can be observed, higher hydrolysis yields were obtained after steam pre-treatment compared to steam explosion pre-treatments. Steam exploded samples have a more accessible surface as a result of the sudden decompression which forces the fibrous material to come apart, separating fibers and fiber bundles (Martin-Sampedro et al. 2014). Fig. 1 indicated that steam explosion pretreatment can significantly increase the ability of the enzymatic hydrolysis. Compared with the untreated sugarcane bagasse, glucose yield of the steam explosion pretreatment sugarcane bagasse increased by $57.86 \%$ with cellulose loadings $30 \mathrm{FPU} / \mathrm{g}$. Furthermore, with the increment of cellulase, the cellulose conversions of steam-exploded sugarcane bagasse increased markedly. The maximum glucose yield $(74.99 \%)$ was obtained with an enzyme loading of $30 \mathrm{FPU} / \mathrm{g}$-cellulose at the substrate loading of $5 \%$ after $72 \mathrm{~h}$, which greatly improve the economic benefits. 


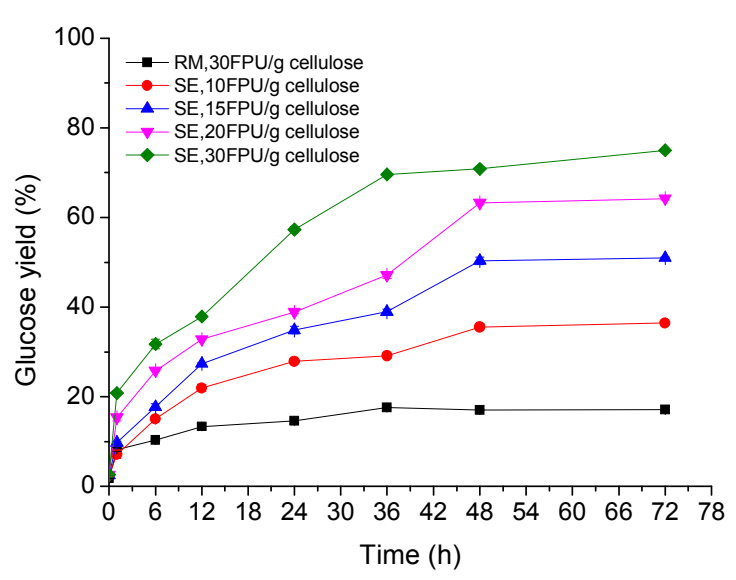

Fig. 1. Glucose yields after $72 \mathrm{~h}$ in the digests of raw material (RM) and steam-exploded sugarcane bagasse (SE) with different enzyme loadings.

Different mechanisms have been proposed in which surfactant addition has a positive effect on the enzymatic hydrolysis of cellulose. Surfactant could change the nature of the substrate, e.g., by increasing the available cellulose surface or by removing inhibitory lignin. Additionally, surfactant could increase the stability of the enzymes and thus reduce the amount of enzyme denaturation during hydrolysis, which is favorable to enzymatic hydrolysis (Helle et al. 1993). Fig. 2 showed that the effect of concentration of natural surfactant Sapindus peel $(0.6,0.9,1.2$, and $1.5 \mathrm{~g} / \mathrm{L})$ on the glucose yield was also investigated. It can be seen that the adding of surfactants can significantly increase the ability of the enzyme during $72 \mathrm{~h}$ hydrolysis. The optimal concentration of Sapindus peel was $1.2 \mathrm{~g} / \mathrm{L}$, and glucose yield is 2.39-fold greater than that of without Sapindus peel. However, the glucose yield decreased when the concentration of Sapindus peel increased to $1.5 \mathrm{~g} / \mathrm{L}$. A suitable amount of surfactant would be preferred in the lignocelluloses saccharification to save the commercial cost in the bioethanol industry (Feng et al. 2012).

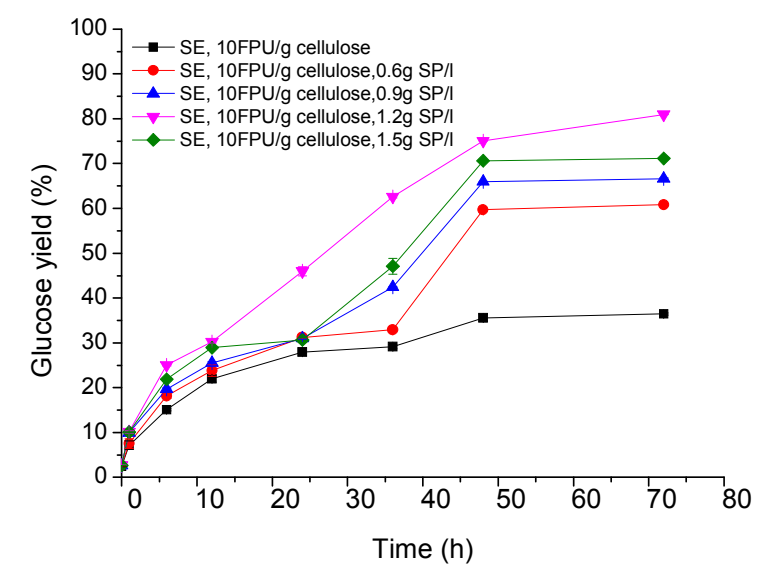

Fig. 2. Glucose yields after $72 \mathrm{~h}$ in the digests of steam-exploded sugarcane bagasse (SE) with different loading of $S a$ pindus peel.

\section{Sugar Production}

The initial rate in the release of glucose from enzymatic saccarification of various conditions is shown in Fig. 3. The initial rate was determined by the amounts of glucose release within $6 \mathrm{~h}$ at the beginning of enzymatic hydrolysis. As can be seen, steam explosion pretreatment and Sapindus peel 
adding had an effective impact on the cellulose conversion compared to untreated and without the adding of natural surfactant Sapindus peel raw materials. For the steam explosion pretreatment materials, the initial production rate of glucose was $2.41 \mathrm{~g}\left(\mathrm{~L}^{-1} \cdot \mathrm{h}^{-1}\right)$ at enzyme loading of $10 \mathrm{FPU} / \mathrm{g}$ cellulose within $6 \mathrm{~h}$, and increased with the increment of the amount of cellulase. The initial production rate of glucose reached the maximum of $5.41 \mathrm{~g}\left(\mathrm{~L}^{-1} \cdot \mathrm{h}^{-1}\right)$ at the amount of $30 \mathrm{FPU} / \mathrm{g}$ cellulose. Meanwhile, initial sugar productivity increased significantly with the increment of natural surfactant Sapindus peel under the same enzyme loading of $10 \mathrm{FPU} / \mathrm{g}$-cellulose and obtained a maximum $\left(3.71 \mathrm{~g}\left(\mathrm{~L}^{-1} \cdot \mathrm{h}^{-1}\right)\right)$ at the amount of $1.2 \mathrm{~g} / \mathrm{L}$, but a decrease when the dosage is $1.5 \mathrm{~g} / \mathrm{L}$, which was probable due to the generation of some inhibitors from Sapindus peel that affected the enzyme activity in the hydrolysis process (Sun et al. 2011).

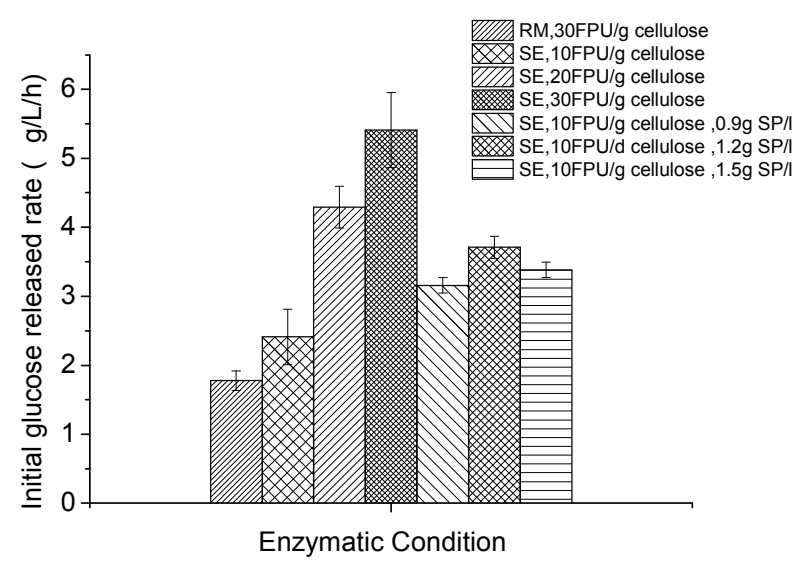

Fig. 3. The initial rate of hydrolysis from raw material (RM) and steam-exploded sugarcane bagasse (SE).

\section{Surface Tensions}

In the enzymatic hydrolysis process, the stability of the enzyme activity is the key factor for affecting cellulose conversion. To compare the influence of Sapindus peel on the enzymatic hydrolysis of steam-exploded sugarcane bagasse, the surface tension of various diluted cellulase solutions with different concentrations $(0,0.6,0.9,1.2$ and $1.5 \mathrm{~g} / \mathrm{L})$ of Sapindus peel was determined. As shown in Fig. 4, the surface tension of the enzymatic hydrolysate of $0 \mathrm{~h}$ and $72 \mathrm{~h}$ with Sapindus peel adding decreased slightly.

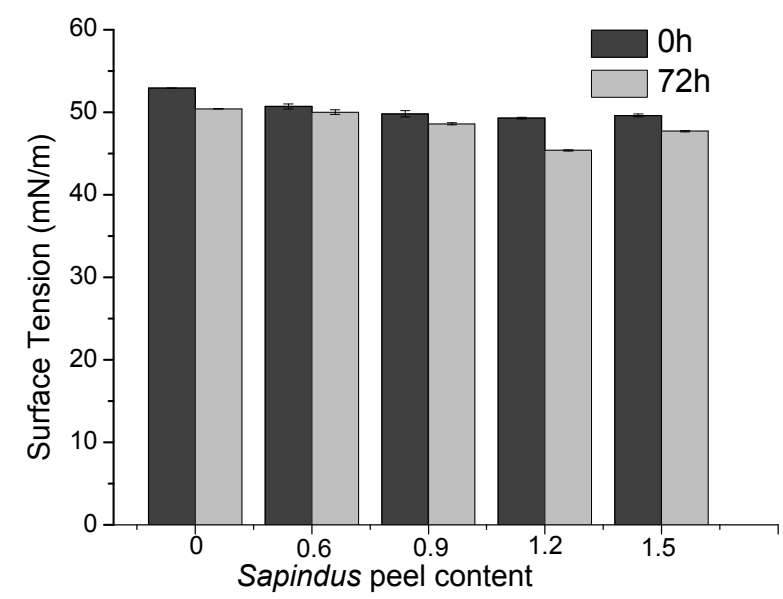

Fig. 4. Surface tensions of steam-exploded sugarcane bagasse with different loading of Sapindus peel. 
The surface tension of solutions with $1.2 \mathrm{~g} / \mathrm{L}$ Sapindus peel decreased markedly (from $49.26 \mathrm{mN} / \mathrm{m}$ to $45.38 \mathrm{mN} / \mathrm{m}$ ), However, the surface tension of solutions with $1.2 \mathrm{~g} / \mathrm{L}$ Sapindus peel decreased from $49.60 \mathrm{mN} / \mathrm{m}$ to $47.69 \mathrm{mN} / \mathrm{m}$ ). The results revealed that Sapindus peel has a beneficial effect on the stability of enzyme activity during the hydrolysis process.

\section{CONCLUSIONS}

Steam explosion pretreatment was a feasible method to treat sugarcane bagasse. The highest glucose yield was achieved at $74.99 \%$, which was increased by $57.86 \%$ with the same enzyme loadings 30 FPU/g cellulose compared with the untreated sugarcane bagasse.

In a certain range, enzyme hydrolysis of steam-exploded sugarcane bagasse can be significantly improved (glucose yield from $36.46 \%$ to $74.99 \%$ ) with the increment of cellulase.

The enzyme loading of sugarcane bagasse hydrolysis could be reduced with addition of Sapindus peel. Sapindus peel can evidently reduce the surface tension of hydrolysis broth and improve the ability of enzyme hydrolysis (glucose yield of $80.99 \%$ ) at an economic concentration $(1.2 \mathrm{~g} / \mathrm{L}$ ).

\section{ACKNOWLEDGEMENT}

The authors are grateful for the financial support of this research provided by the State Forestry Administration (2012-03).

\section{REFERENCES}

[1] Andrade, RR. \& Filho, R.M. \& Costa A.C. \& Rabelo, S.C. 2014. Alkaline hydrogen peroxide pretreatment, enzymatic hydrolysis and fermentation of sugarcane bagasse to ethanol. Fuel136: 349357

[2] Ahvazi, B. \& Radiotis, T. \& Bouchard, J. \& Goel, K. 2007. Chemical pulping of steam exploded mixed hardwood chips. J. Wood Chem. Technol27: 49-63

[3] Boscolo, M. \& Silva, R. da. \& Perrone, O.M. \& Villena, M.A. \& Nunes, C. da. CC. \& Bocchini-Martins, D.A. \& Gomes, E. \& Moretti, MM. de. S. 2014. Pretreatment of sugarcane bagasse with microwaves irradiation and its effects on the structure and on enzymatic hydrolysis. Applied Energy 122: 189-195

[4] Cao, S. \& Aita, GM. 2012. Enzymatic hydrolysis and ethanol yields of combined surfactant and dilute ammonia treated sugarcane bagasse. Bioresource Technology131: 357-364

[5] Feng, Y. \& Ji, L. \& Liu, H.Q. \& Jiang, J.X. 2012. Enhanced hydrolysis of furfural residues by Trichoderma cellulases with addition of natural surfactant Tea Saponin, advanced Materials Research Vols424-425: 871-875

[6] Hofsetz, K. \& Silva, M.A. 2012. Brazilian sugarcane bagasse: Energy and non-energy consumption. Biomass and Bioenergy46: 564-573

[7] Helle, S.S. \& Duff, S. J. \& Cooper, D.G. 1993. Effect of surfactants on cellulose hydrolysis.

Biotechnology and Bioengineering42: 611-617.

[8] Kim, H.J. \& Kim C.J. \& Kim, S.B. 2007. The Effects of Nonionic Surfactants on the Pretreatment and Enzymatic Hydrolysis of Recycled Newspaper. Biotechnology and Bioprocess Engineering12: $147-151$

[9] Martin-Sampedro, R. \& Eugenio, M.E. \& Moreno, J.A. \& Revilla, E. \& Villar, J.C. 2014. Integration of a kraft pulping mill into a forest biorefinery: pre-extraction of hemicellulose by steam explosion versus steam treatment. Bioresource Technology 153: 236-244.

[10] Sun, R. \& Song, X.L. \& Sun, R.C. \& Jiang, J.X. 2011. Effect of lignin content on enzymatic hydrolysis of furfural residues. BioResources6: 317-328

[11] Tao, L. \& Aden, A. \& Elander, R.T. \& Pallapolu, V.R. \& Lee, Y.Y \& Garlock, R.J. et al.. 2011. Process and technoeconomic analysis of leading pretreatment technologies for lignocellulosic ethanol production using switchgrass. Bioresource Technology102: 11105-14 
[12] Yu, H.L. \& Tang, Y. \& Xing, Y. \& Zhu, L.W. \& Jiang, J.X. 2013. Improvement of the enzymatic hydrolysis of furfural residues by pretreatment with combined green liquor and hydrogen peroxide. Bioresource Technology147: 29-36

[13] Yang, B. \& Wyman, C.E. 2004. Effect of xylan and lignin removal by batch and flowthrough pretreatment on the enzymatic digestibility of corn stover cellulose. Biotechnology and Bioengineering86: 88-98.

[14] Zhao, D.Q. \& Jiang, J.X. 2013. Studies on surface activity of sapindus mukurossi sponin and simultaneous fermentation refining process of water extraction. Beijing Forestry University: 7-9 